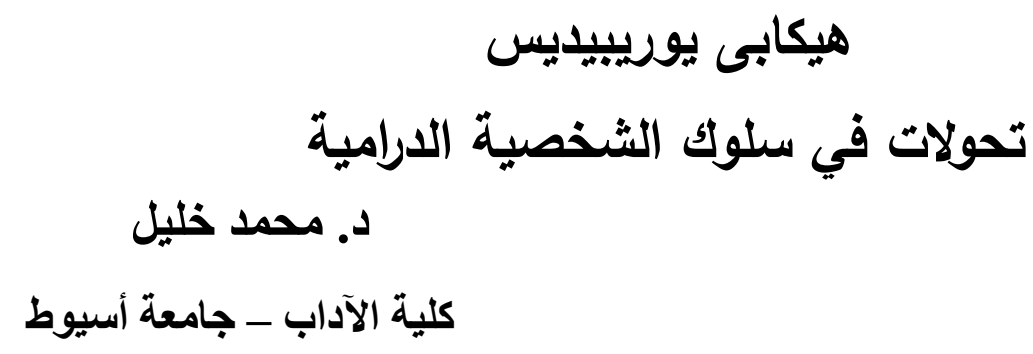

\begin{abstract}
This research is focusing on the stage after the fall of Troy, where Hecuba and Polyxeni were standing as the last members of the Trojan royal family among the ruins of Troy.
\end{abstract}

Queen Hecuba had to suffer and endure the sacrifice of her daughter Polyxeni for the sack of Achilles, as she witnessed before the death of her husband Priamus and the slavery of her daughter Kassandra.

Euripides in his play is shedding the light on two different struggles:

- First: the struggle between Hecuba and Odysseus, when Hecuba failed to convince him not to sacrifice her daughter. And that was the first main characteristic of the conquered queen. As she appeared weak and pitiful.

- Second: the struggle between Hecuba and Agamemnon, when she failed to convince him to take revenge from Polymestor the killer of her son Polydorus. Through that struggle Hecuba turned into a different character. Hecuba is not only demanding revenge but also ordering Agamemnon to keep silent about what she wants to do.

Revenge is accomplished by Hecuba and captives of Troy, women killed sons of Polymestor before blinding his eyes. Blind Polymestor starts all of a sudden to predict the death of Agamemnon and the awful end of Hecuba.

Sudden changes in the characters of both Hecuba and Polymestor are radical in the play. And gods do not seem to play any role in the whole play, which is prototype for Euripides himself. 


\section{هيكابي يوريبيايس}

لماذا كل هذا العويل والنحيب من أجل طروادة! لماذا لا يكون مقبولا أن نسقط طروادة، ويسقط معها من كان يحكمها!

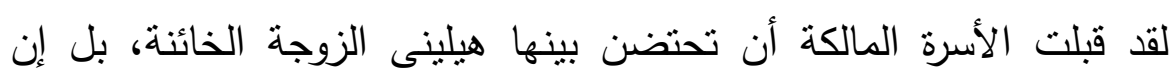

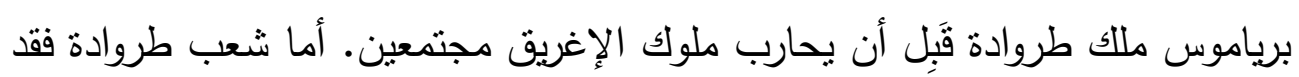
استجاب لنداء الخيانة وخضع لإرادة الخيانة والفساد.

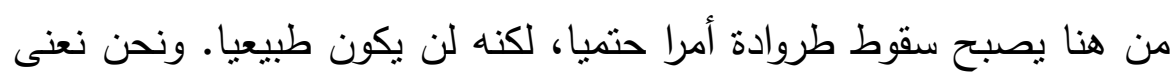

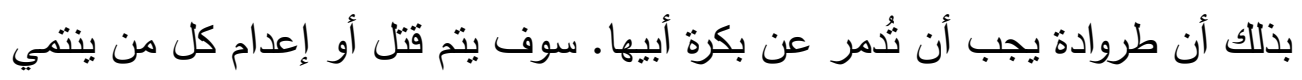

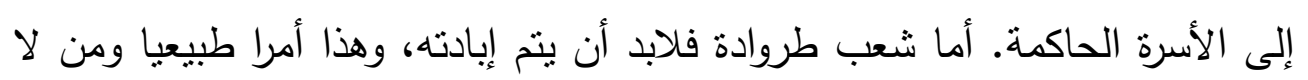
يجده كذللك فعليه أن يُحكّمٍ عقله لا مشاعره. إن ما يتبقى لنا بعد سقوط طروادة هو أن نقف على على أطلالها ونحاول جاهدين

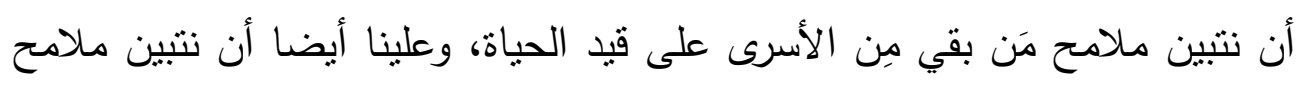

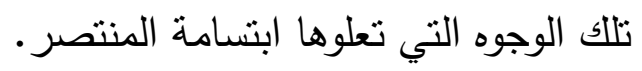
هنا وعلى أنقاض طروادة ترقد الملكة هيكابى، زوجة برياموس ملك طروادة

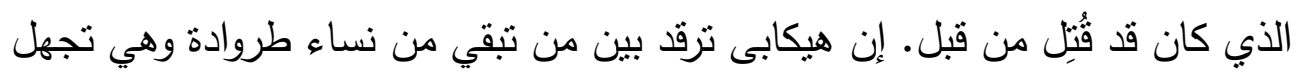

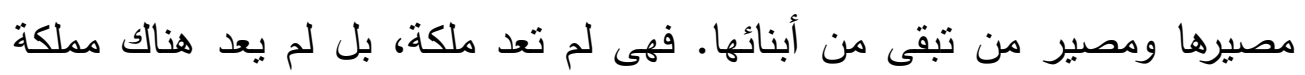

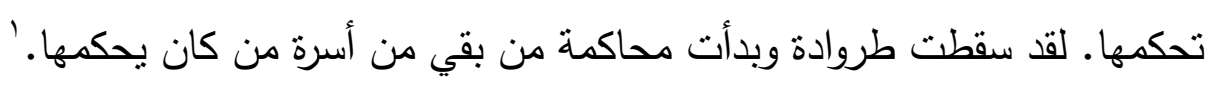
من هنا يبدأ يوريبيديس مسرحيته التي تحمل اسم هيكابى. ومن هنا يبدأ بحثنا الذي سنحاول فيه أن نناقث النقاط التالية:

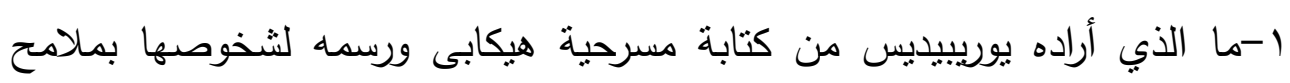

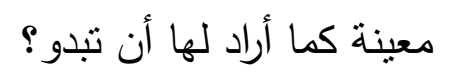

'تقوم مسرحية يوريبيديس على أسطورتين منفصلتين: تقديم بوليكسينى قربانا على قبر أخيالليوس ومقتل بوليدوروس

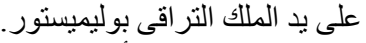

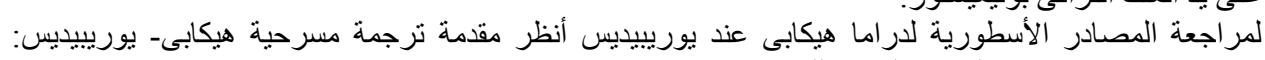

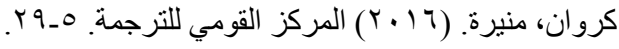


ץ-كيف يمكن لنا أن نحلل شخصية هيكابى وتحولها المفاجئ من صورة الضحية إلى صورة الثخصية الساعية للانتقام؟ r-ما هو المغزى من النبوءة في المسرحية، وما هو الدور الذي تلعبه في مجريات الأحداث؟ مون

ع-ماذا يمثل عنصر المفاجأة في مسرحية هيكابى؟

تبدأ مسرحية "هيكابى" بالإعلان عن جريمتين. الأولى وقعت بالفعل ويرويها شبح الثخص الذي تم قتله، وهو بوليدوروس. أما الثانية فإنها تُعبر عما سيقع في هي

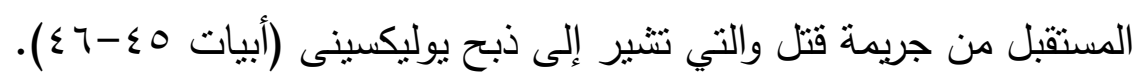
أما هيكابى فإن حزنها على ابنتها التي سوف تُذبح على قبر أخيلليوس وإحساسها بمدى الظلم الواقع عليها، يجعلاها تُعلن أمام أوديسيوس أن هيلينى هي من يستحق العقاب : n (n)

هيكابى: وكان أجدر بها أن يطلب أن ثُنَبح هيلينى قريانا على قبره.

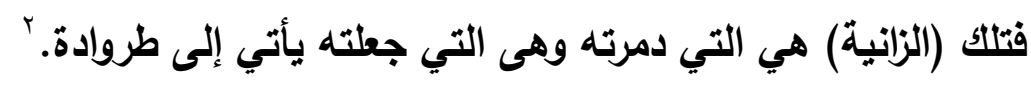

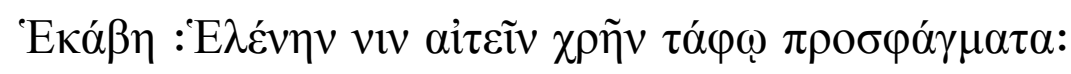

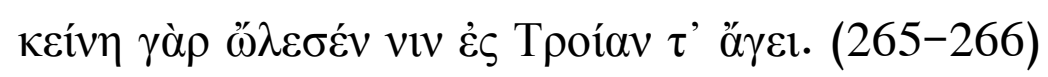
إن هيكابى تطلب من أوديسيوس أن يقتل هيلينى بدلا من بوليكسينى. وكأنها بذلك

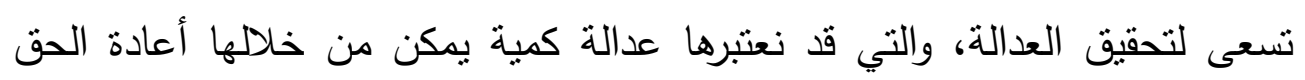
والتوازن بالنظر إلى من هو البريء ومن هو الجاني. لكننا قد نعلم أن هيلينى ليست وحدها من بيتحق العقاب. فمن وراء هيلينى يقف باريس الذي أغواها وحرضها على الهروب من قصر زوجها الملك مينيلاؤس

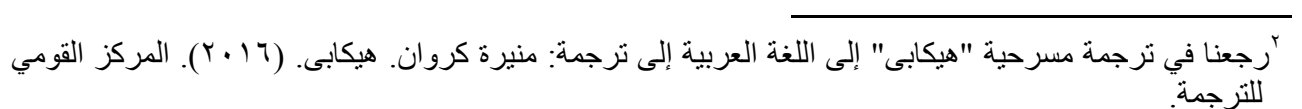
${ }^{3}$ Love, H. (2009). Introductions and Translations to the Plays of Sophocles and Euripides. Vol. 1. Cambridge Scholars Press. P. 9. 


\section{هيكابي يوريبيليس}

ومن وراء هيلينى وباريس تقف الأسرة الحاكمة بطروادة ومن ورائهما يقق شعب طروادة الذي سواء كان قد بارك وجود هيلينى في طروادة أم لا، لكنه في النهاية سيدفع الثمن غاليا بسقوط مدينته وتدميرها. من هنا يصبح ما نطالب به هيكابى أمرا مرفوضا من خلال العدالة التي وناي

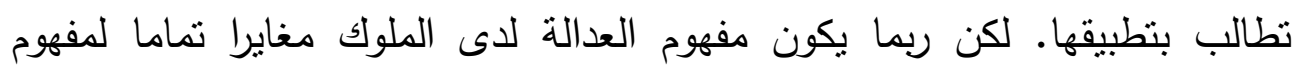

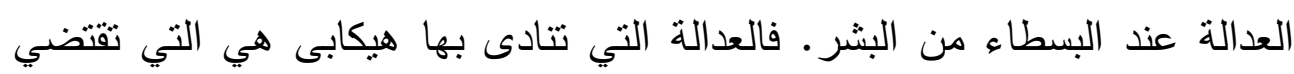

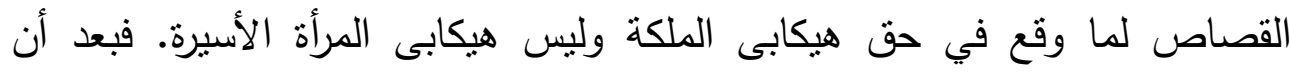

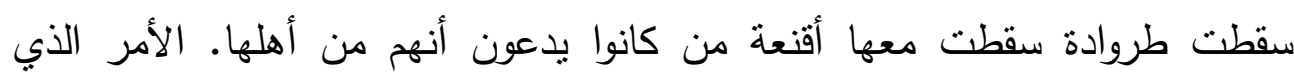

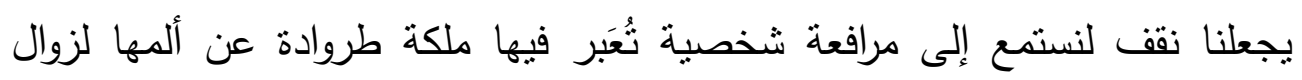

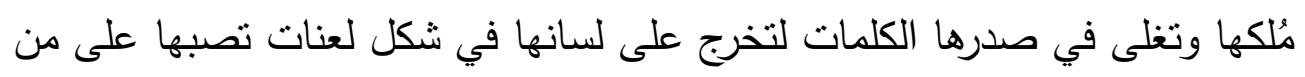

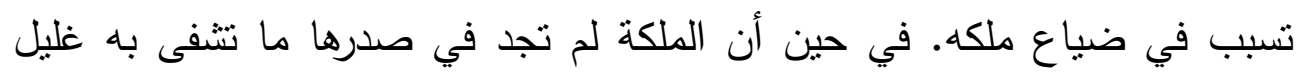

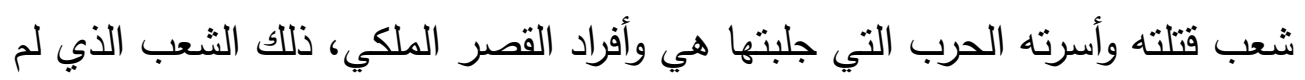
يتخذ قرارا بدخول تلاك الحرب أو حتى رفضها.

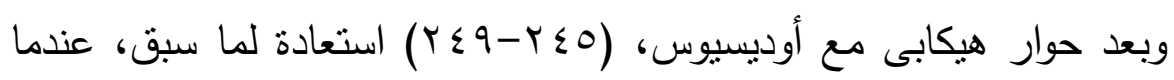

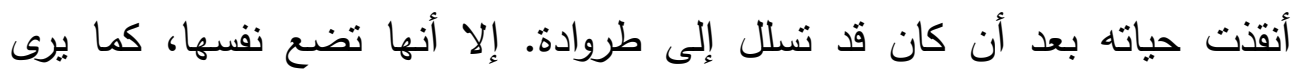
Schuren

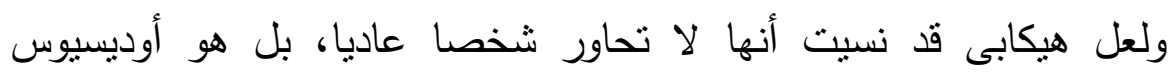

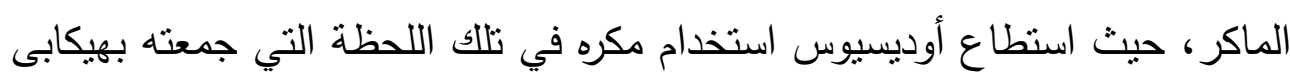

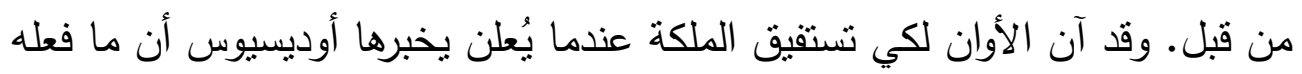

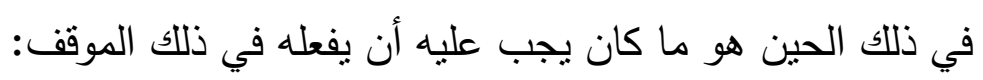

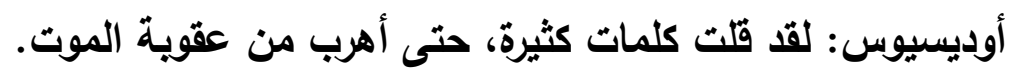

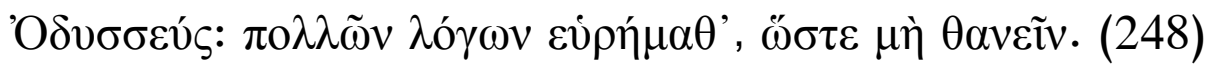

${ }^{4}$ Schuren, L. (1980). Shared Storytelling in Euripidean Stichomythia. Leiden-Boston. PP.121-22. 
لقد كان رد أوديسيوس بمثابة الصدمة بالنسبة لهيكابى الملكة التي لم تكن تدري وما زالت أن الحرب خدعة، وأن أوديسيوس لم يقل سوى ما كان يقتضيه الموقف وتقرضه ظروف الحرب. أما هيكابى فقد آثرت أن تخدع نفسها بتصديقه حين

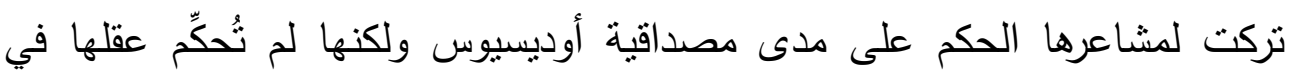
إدراك دقة الموقف الذي جمعها بأوديسيوس. وهكذا أكملت هيكابى صورة أفراد القصر الملكي في طروادة. فمن قبل قرر باريس أن يخضع لمشاعره ويأتي بهيلينى زوجة مينيلاؤس بسبب هوى اعترى قلب الأمير الثاب وخيانة زوجة مينيلاؤس لزوجها، ثم قبول القصر الملكي بدون تردد أن يحتضن وبرعى هذه العاطفة المحرمة بعد أن غلَّب أب أن ملك طروادة نفسه حكم القلب على العقل. من هنا كان طبيعيا أن نرى هيكابى نفسها

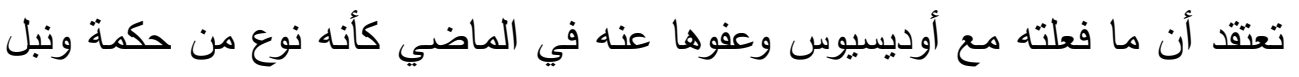
الملوك. بَيد أنه لم يكن سوى تصرف يكثف عن غياب الحكمة وتشلط المشاعر المندفعة في اتخاذ أدق القرارات تجاه واحد من أهم أعداء طروادة، في وقت استحكمت نيت فيه حلقات الحرب.

إن ما تستمر هيكابى في توجيهه لأوديسيوس من اتهامات توضح كيف أنها لا زالت غير قادرة على تحكيم عقلها، بل يكثف كيف أن الملكة تكيل الأمور بمكيالين، فقي حين تقول: هيكابى: يا من تقومون بإيذاء أصدقائكم دون أن تثوققوا لحظة للتفكير

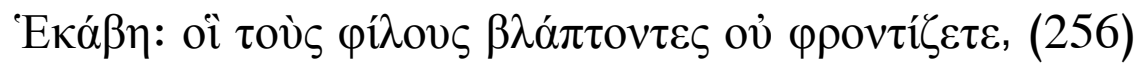
نراها قد نسيت أو تتاست ما فعله باريس بمينيلاؤس عندما استضافه في قصره من قبل. أما أوديسيوس فهو يعتبر أن التضحية ببوليكسينى هي العدالة لما يحتله وأخيلليوس من مكانة عالية:

${ }^{5}$ Worman, N. (2002). The Cast of Character. Style in Greek Literature. University of Texas Press. P.121. 


\section{هيكابي يوريبيديس}

\section{أوديسيوس: وأخيلليوس بالنسبة لنا، يا سيدتي، يستحق التقدير.}

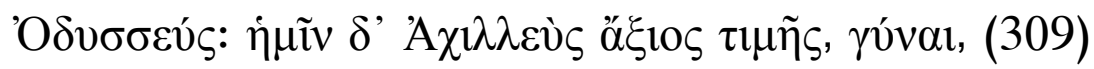
أما ما أقدمت عليه هيكابى من جذب الانتباه لموت بوليكسينى إنما كانت

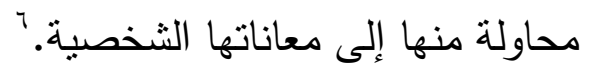
ولنا أن نلاحظ هنا أن مباركة أوديسيوس التضحية بهيلينى أمر طبيعي لا لانهان

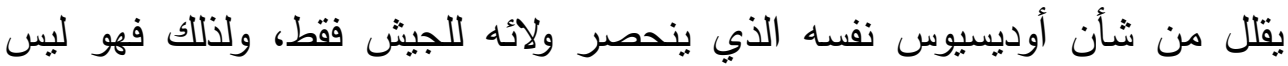

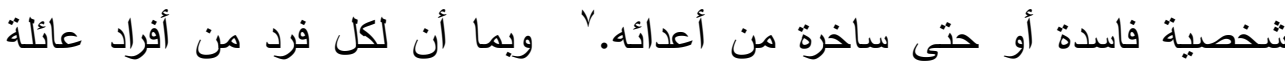

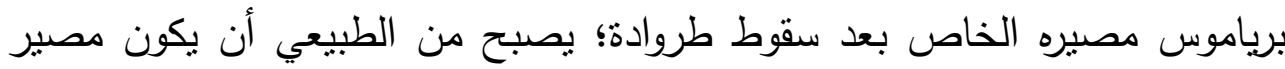

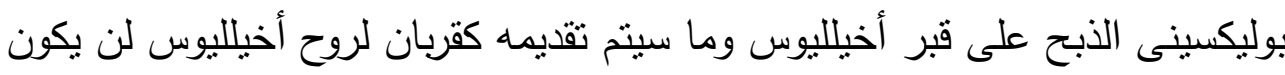

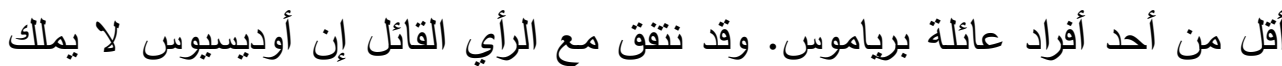
شخصية المتآمر الحقيقي ولكنه يبدو خطيبا مفوها يحاول تبرير ما تم الوصول إليه من قرار بقتل بوليكسينى. حتى عندما نظلى عن مساعدة هيكابى في إنقاذ ابنتها. لكن الكن

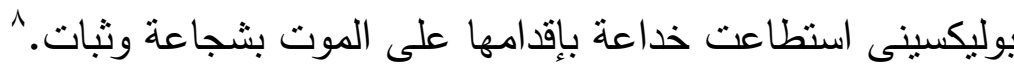

$$
\text { بوليكسينى: ولكتني أريد أن اموت. }
$$

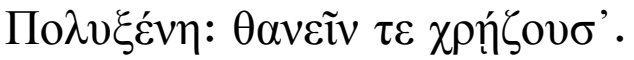

وهنا قد نطرح سؤالا وهو لماذا لا يتم التضحية بهيكابى زوجة ملك طروادة

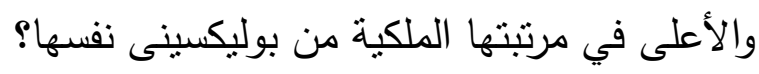

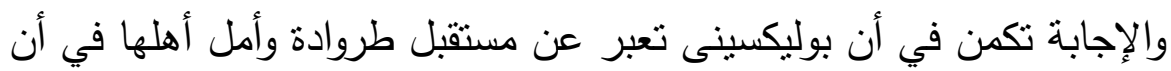

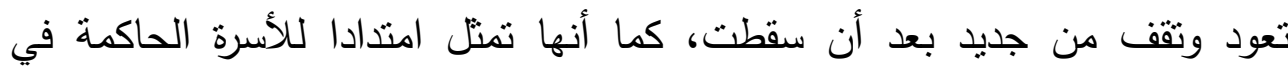

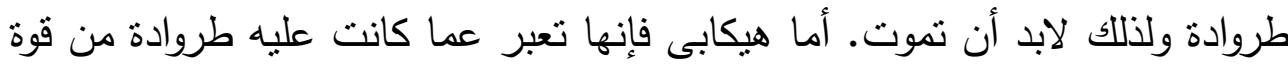

${ }^{6}$ Shuren (1980) 69.

${ }^{7}$ Kastely, J. L. (1993)., "Violence and Rhetoric in Euripides' Hecuba", PMLA, Vol. 108, No. 5, P.1037.

${ }^{8}$ Chong-Gossard, J. H. 2008., “Gender and Communication in Euripides' Plays. Between Song and Silence", In Boter, G. J \& Others. Monographs on Greek and Roman Language and Literature. Mnemosyne Supplements, Vol 296, P. 228. 
ورخاء، أما الآن فإنها تعبر عما آلت إليه من هزيمة ودمار • إذا هيكابى قد تمثل لنا العلاقة بين ماضي طروادة القوية وحاضر طروادة المهزومة.

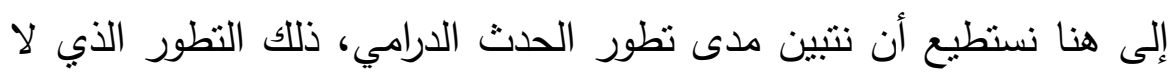
يبدو للآلهة أي دور فيه. أي أنه لا يوجد مكان لما يسمى بالحتمية الدينية في أمر لئي

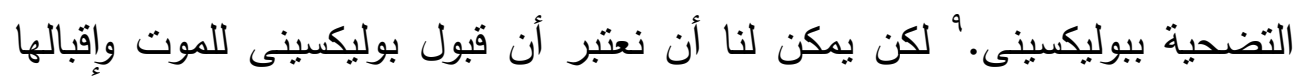
عليه هو ما جعلها رمزا فريدا للبراءة، وهذا ما انطبع في قلب وعقل الجيوش الإغريقية، حيث أنها تحولت من مجرد إنسان حي إلى رمز للطهر والبراءة. ' كما إن إقبال بوليكسينى على الموت جعلها تتحول من مجرد ضحية سلبية إلى شخصية بطولية.' 'أما هيكابى فقد بدت وكأنها محارب يطلق سهامه فلا تصيب أي من أهدافها. ب' الأمر الذي عبرت عنه هيكابى بعد أن فنثلت في اقناع أوديسيوس بعدم ذبح ابنتها بقولها:

\section{هيكابى: تطيش سهام عقلي بلا جدوى.}

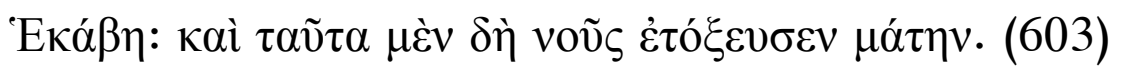
بعد فثل هيكابى في إقناع أوديسيوس بقتلها هي الأخرى مع ابنتها، تودع بوليكسينى أمها وداعا مؤثرا جعل بعض النقاد يرشح هذا المشهد كأفضل مشاهد

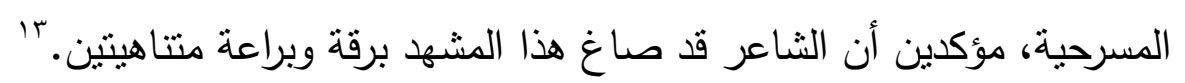
بينما كانت هيكابى تظن أن مصائبها قد انتهت بموت بوليكسينى، تظهر الخادمة ومعها بعض الرجال الذين يحملون جسد بوليدوروس ابن هيكابى الذي كان

${ }^{9}$ Abrahamson, E. L. (1952).” Euripides' Tragedy of Hecuba", TAPhA, Vol. 83, P.122.

${ }^{10}$ Kastely (1993) 1039.

${ }^{11}$ Conacher, D. J. (1961). "Euripides' Hecuba", AJPh, Vol. 82, No. P.6.

${ }^{12}$ Sullivan, S. D. 2000). Euripides' Use of Psychological Terminology. Queen's University Press. P. 54.

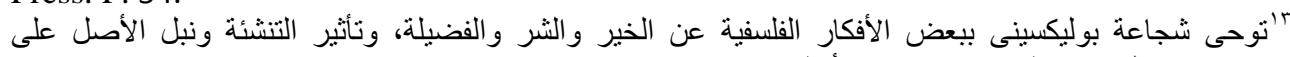

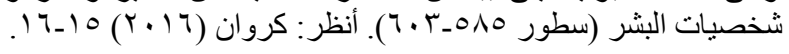




\section{هيكابي يوريبيديس}

برياموس قد أرسله إلى بوليميستور ملك تراقيا ليحميه، باعتباره وريث عرش طروادة،

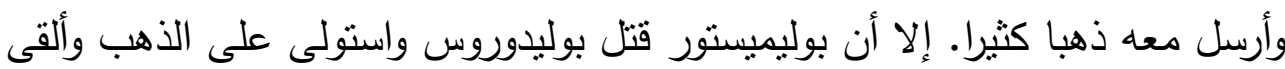
بجثته في البحر، حيث عثرت عليها الخادمة وأتت بها إلى هيكابى التي لم تكن قد تمالكت نفسها بعد صدمة ذبح ابنتها بوليكسينى. وأول العبارات التي ألقتها هيكابى وهي تتعى في ذهول موت ابنها كانت عبارة: هيكابى: أين حق الضيف (في الحماية)؟

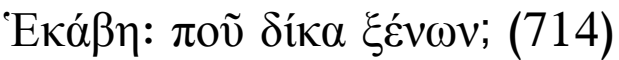
وعندئذ بدأت تفكر في أجاممنون كقوة التي تحتاجها للانتقام لابنها المقتول: هيكابى: ولكنى لن أتمكن من الانتقام لأولادي من دون مساعدته.

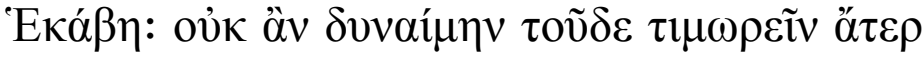

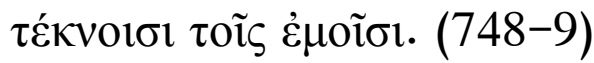

ثم تؤكد على رغبتها في الأخذ بالثأر مهما كان الثن، فتقول: هيكابى: إنتي أرغب في الانتقام من

\section{المجرمين ويعدها أقضي حياتي كلها أَمة.}

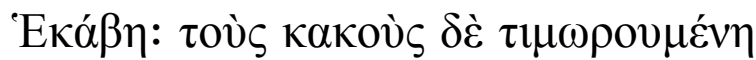

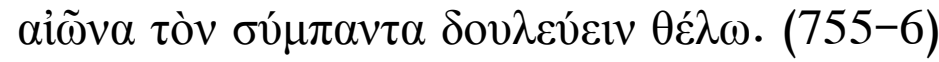

وهكذا فقد وجدت هيكابى ضالتها في أجاممنون الذي سيمنحها القوة بموافقته

على الانتقام لمقتل ابنها، على عكس ما قد يحدث لو كان أوديسيوس هو الحاضر ــأ.

ومن الملاحظ أنه منذ أن تلقت هيكابى نبأ مصرع بوليدوروس فقد تحولت من حالة الضعف واليأس إلى حالة القوة والرغبة الدامية في الانتقام. الأمر الذي يجعلنا نتفق 
مع Reckford في أن مسرحية هيكابى تتقسم إلى جزئين مختلفين، بل ومتتاقضين في اللهجة والوتيرة:

- الجزء الأول: يسيطر عليه الحزن والخوف والخسارة وتسير فيه الأحداث

$$
\text { ببطيء. }
$$

- الجزء الثاني: تزداد فيه الحدة بشكل عنيف وتصيب الجمهور درجة من الإثارة

$$
\text { تقف ورائها رغبة هيكابى في الانتقام. }
$$

وكان برياموس قد أرسل بوليدوروس إلى بوليميستور محملا بالذهب ليكون

$$
\begin{aligned}
& \text { تحت حمايته، وهو ما تقصح به هيكابى لأجاممنون: } \\
& \text { هيكابى: لقد أرسله إليه ليحرس الذهب الملعون. }
\end{aligned}
$$

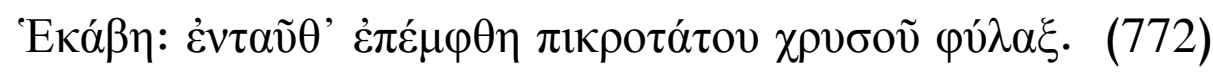
لعل ما يمكن أن بسمى ب "عنصر المفاجأة" هو ما اعنرى هيكابى من القوة فجأة

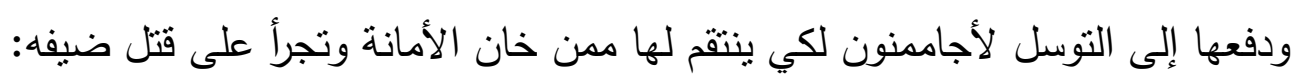

$$
\text { هيكابى: فلتساعدني }
$$

$$
\text { ولتنتقم لي من ذلك الرجل. فئل }
$$

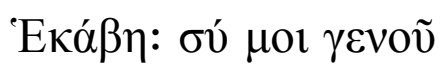

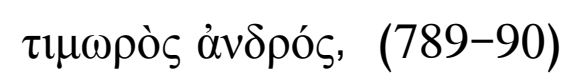

هيكابى: الذي كثيرا ما شاركنا الطعام في منزلي

ونال أحسن ضيافة وكنا نعتبره أفضل أصدقائنا.

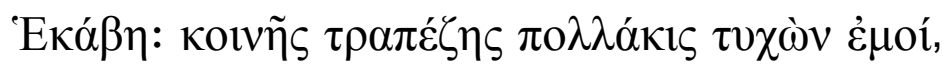

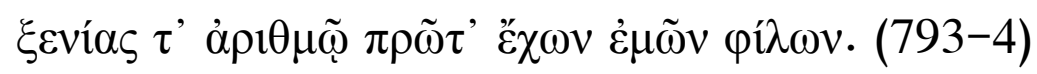

${ }^{15}$ Reckford, K., (1991), "Pity and Terror in Euripides' "Hecuba"”, Arion, Third Series, Vol. 1, No. 2, P.30. 


\section{هيكابي يوريبيديس}

ولا شك أن الخيانة هي العنصر الرئيس في كل ما سبق. لقد سقطت طروادة بسبب خيانة باريس الضيف لمضيفه مينيلاؤس، وضاع أمل طروادة وملكتها الأسيرة بسبب خيانة بوليميستور لضيفه بوليدوروس وقتله إياه. وهنا تعبر هيكابى عن إيمانها العميق بعدالة السماء وقوة الآلهة في تحقيق العدل من خلال القانون السماوي الذي يحكم كل شيء:

هيكابى: ريما أكون مجرد أمة لا حول لها ولا قوة ولكن الأرباب أقوياء، وأقوى من هوَلاء الأرياب القانون. فعن طريق القانون نعرف الأرياب ونستطيع التفرقة بين الظلم والعدل أثناء حياتنا.

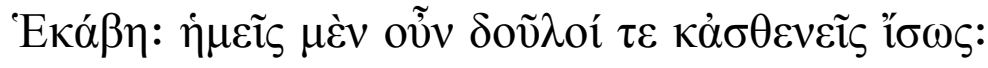

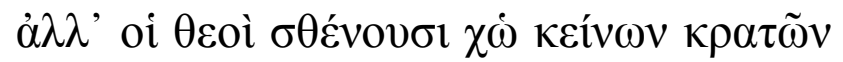

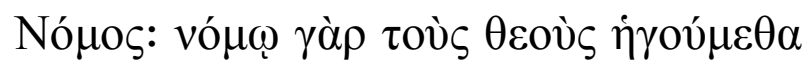

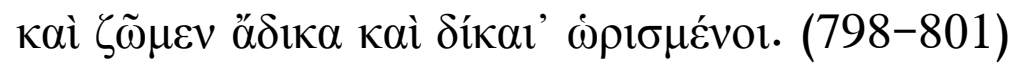

ويرى Kastely" أن تضرع هيكابى يُعد أقوى نقطة في الحبكة الدرامية خاصة عندما تشير للقانون Nópos". هنا يشير Kirkwood" إلى أن هيكابى قد سقطت ضحية نتيجة تمسك أوديسيوس بالقانون من ناحية، ولتخلي أجاممنون عنه من ناحية أخرى. من هنا يصبح هذا التحول في شخصية هيكابى بمثابة فجيعتها الكبرى. إذا، فالقانون الذي يحكم كل شيء، حتى الأرباب نفسه، كان قد تسبب في قتل بوليكسينى ومنع هيكابى من أن تدفع عنها الموت، والآن سيمنح القانون ذاته هيكابى الحق في الانتقام من قاتل ابنها وسيجعل أجاممنون يتتحى جانبا ويفسح الطريق لهيكابى لتحقق ما تصبوا إليه.

${ }^{16}$ Kastely (1993) 1042.

${ }^{17}$ Kirkwood, G. M. (1947), " Hecuba and Nomos”, TAPhA, Vol. 78, P. 68. 
قد لا ينكر أجاممنون حق هيكابى في فجيعتها وآلامها ورغبتها في الانتقام، لكن لا يبدوا لنا أنه قد يستطيع مساعدتها، وله بالطبع أسبابا تمنعه من ذلك: أجاممنون: إنتي شخصيا أشعر بالثفقة على ابنك وعلى حظك السيء

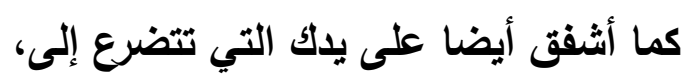
وأتمنى من أجل نصرة الأرباب والعدالة أن ينال ذلك الصديق عديم التقوى جزاء فعلته، ولكن إذا فعلت ما تريدين فسوف أبدو على صواب من وجهة نظرك، ولكن بالنسبة للجيش فسوف يتهني بأنني أردت قتل الملك التراقى بسبب حبي لكاساندرا.

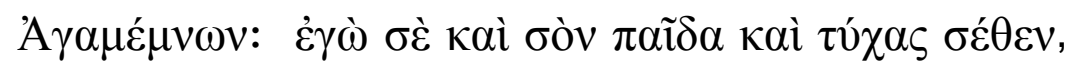

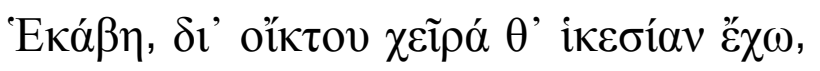

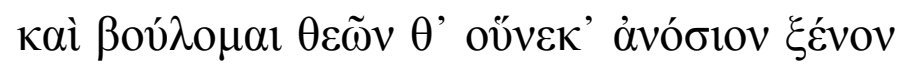

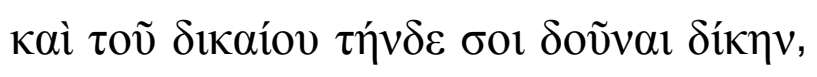

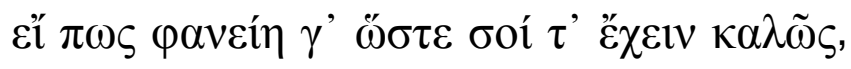

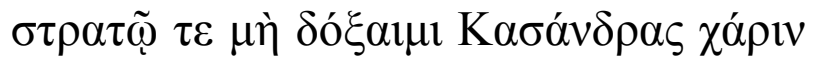

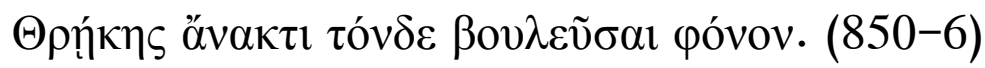
قد نختلف هنا مع بعض الدارسين الذين اعتبروا أن إثارة أجاممنون لكاساندرا تعبر عن أنه قد قرر السماح لهيكابى بالانتقام من بوليميستور فقط من أجل إرضاء

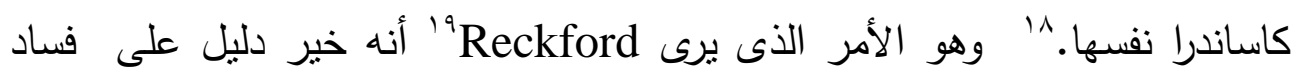
أجاممنون نفسه، فكساندرا تتحول لتصبح نوع من الرشوة لقائد الجيوش الإغريقية.

${ }^{18}$ Abrahamson (1952) 125-6. Rehm, R. (2002), The Play of Space. Spatial Transformation in Greek Tragedy. Princeton University PressP.181.

${ }^{19}$ Reckford (1991) 63. 


\section{هيكابي يوريبيديس}

وقد يكون سبب اختلافنا مع الرأي القائل بفساد أجاممنون، أو اعتبار كاساندرا هي

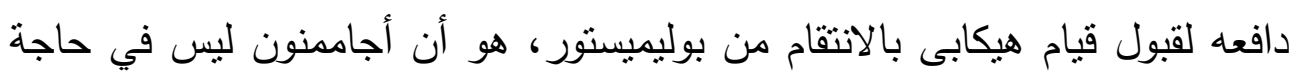

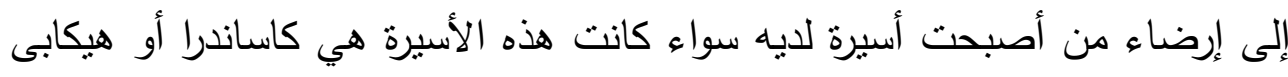

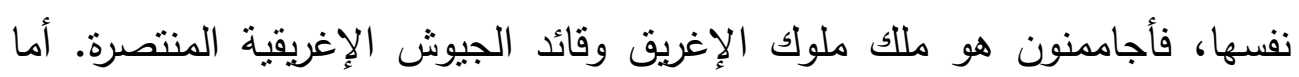

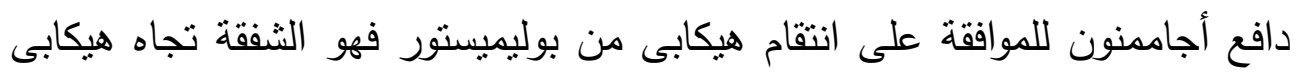

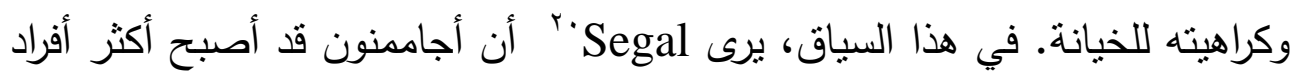
الجيوش الإغريقية رقة.

من ناحية أخرى؛ فلعلنا لا ننسى أن تحالف الجيوش الإغريقية ضد طروادة

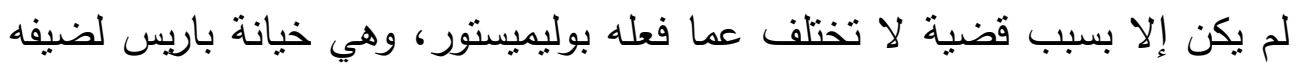

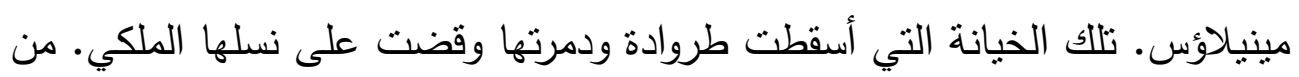

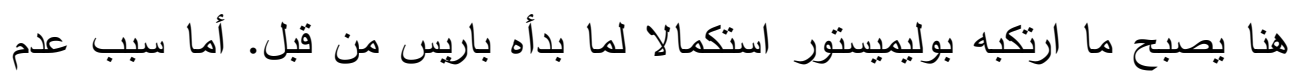

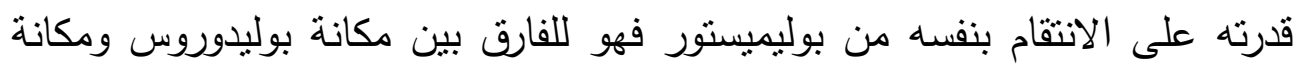

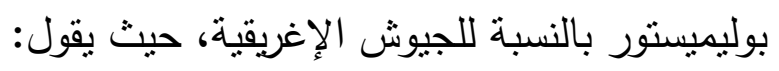

\section{أجاممنون: فالجيش يعتبر هذا الرجل صديقا له وحليفا}

بينما القتيل عدوه.

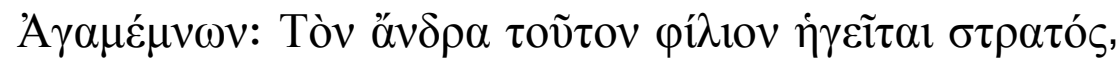

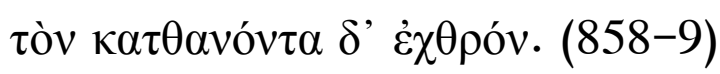

والمذهل في الحوار الذي دار بين هيكابى وأجامهنون أنها، وهي الملكة الأسيرة التي لهاي

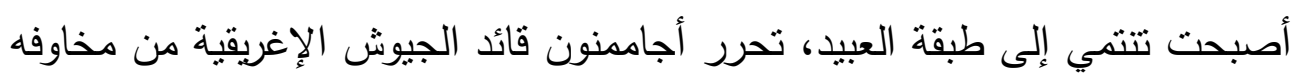

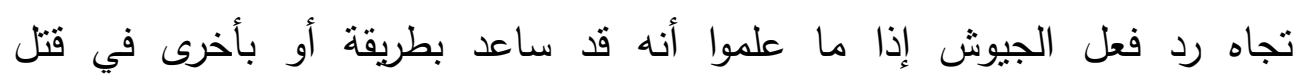
بوليميستور : - اه

${ }^{20}$ Segal, C. (1989), "The Problem of the Gods in Euripides' Hecuba", Materiali $e$ discussioni per l'analisi dei testi classici, P.17. 


\section{هيكابى: وحيث أنك تخشى حشود الجنود الذين تحكمهم فسوف أحررك من ذلك الخوف.}

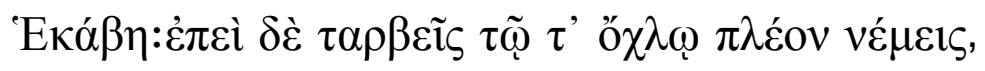

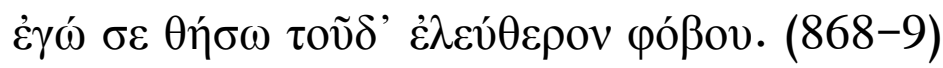

ويعد عرض هيكابى لأجاممنون نوعاً من التلاعب الساخر الذي يخفى في

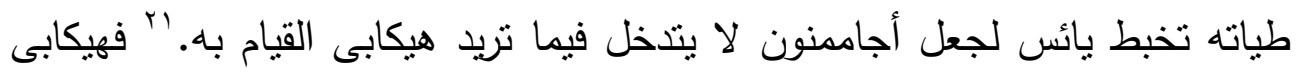

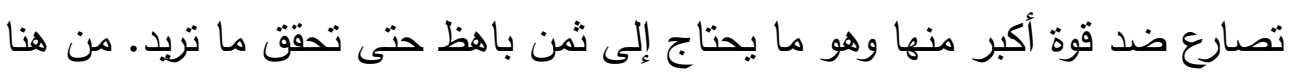

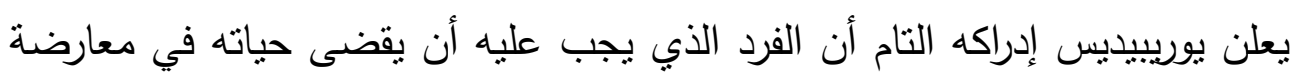

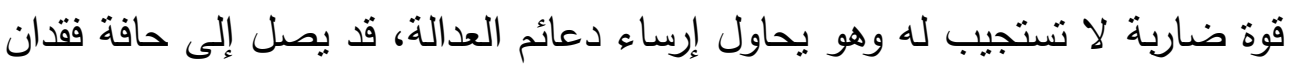

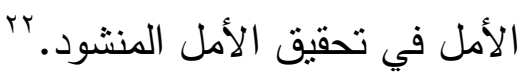

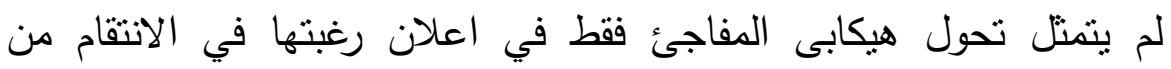

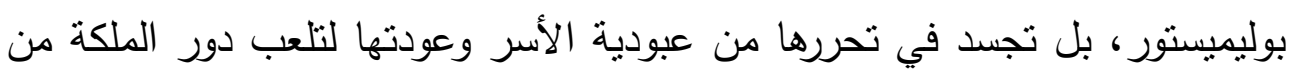

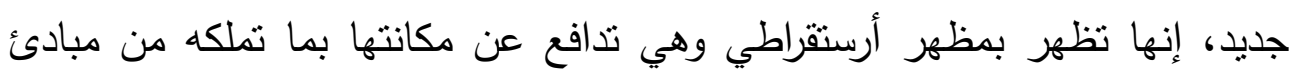

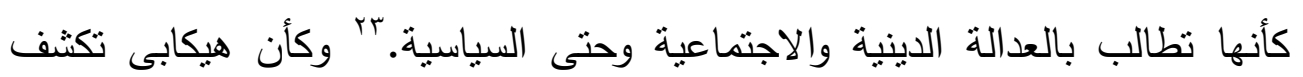

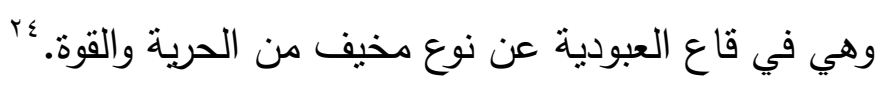

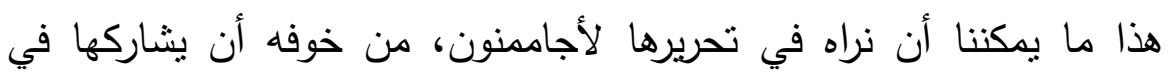

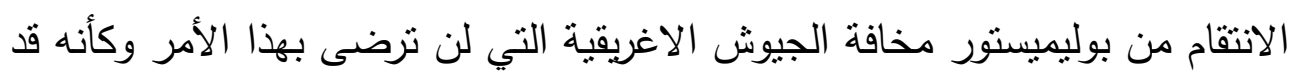

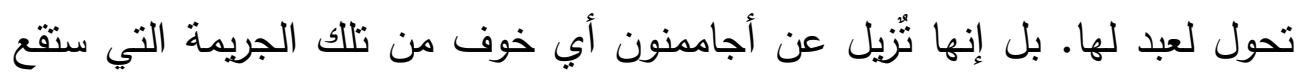

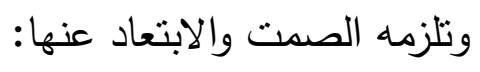

${ }^{21}$ Sansone, D. (2012). Greek Tragedy and the Invention of Rhetoric. Wiley-Blackwell, 122, Kastely (1993) P.1042.

${ }^{22}$ Kastely (1993) 1046.

${ }^{23}$ Foley, H. P. (2001). Female Acts in Greek Tragedy. Princeton University Press. P.285.

${ }^{24}$ Reckford (1991) 36. 


\section{هيكابي يوريبيديس}

\section{هيكابى: ولكن لتحفظ سرى إذا ما خططت أمرا}

\section{ضد من قتل ابني دون أن تثاركني في تنفيذه.}

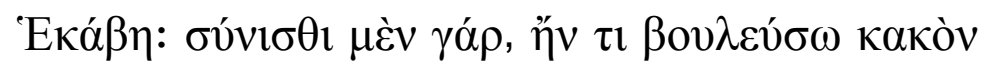

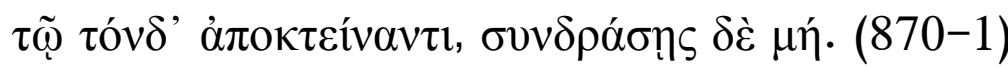

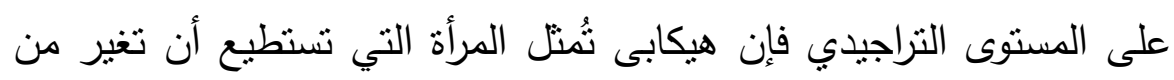

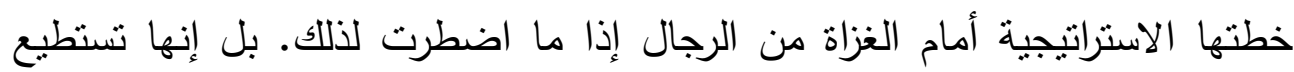

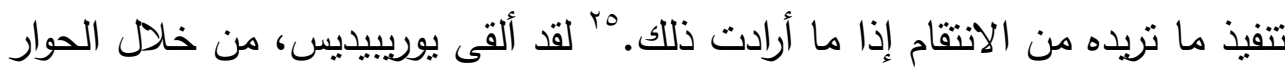

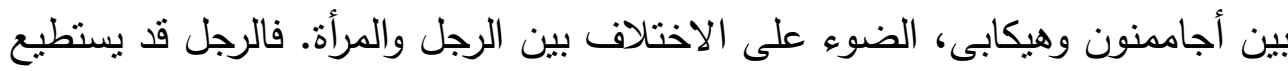

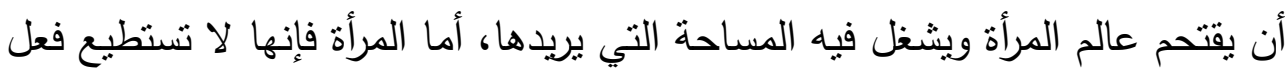

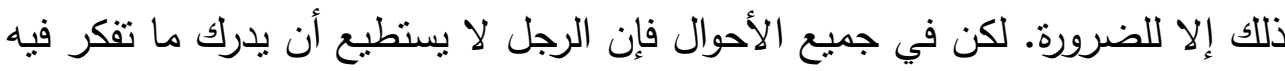

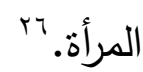

لقد كان لهيكابى جدالا سابقا مع أوديسيوس جعلها تقع في حيرة بائسة. لكن

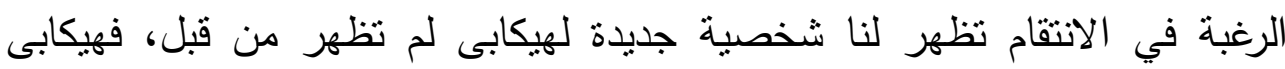

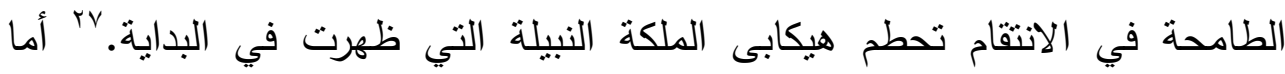

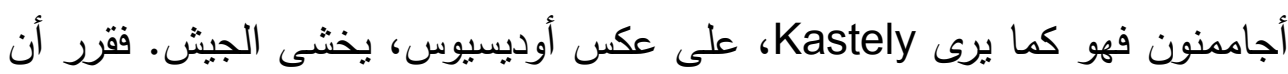

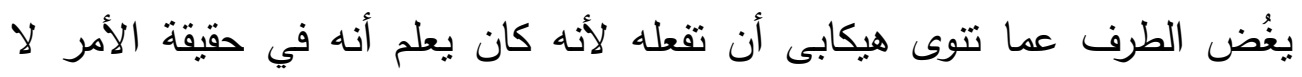

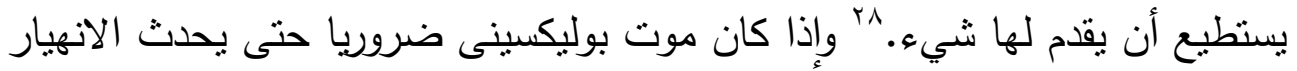

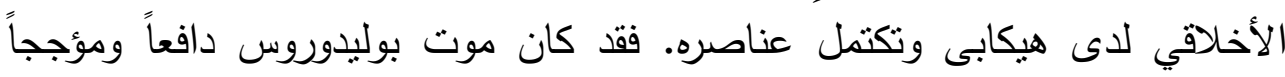

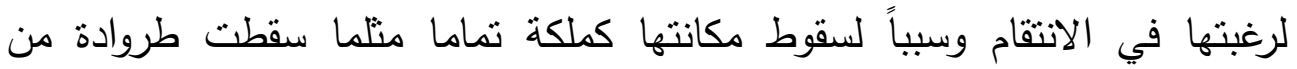

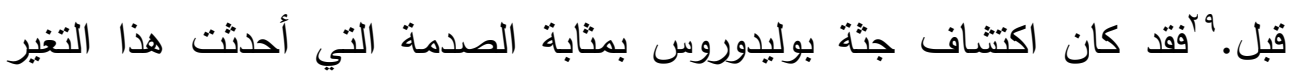

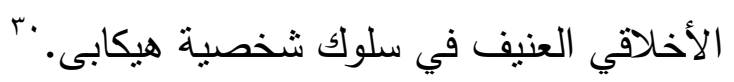

${ }^{25}$ Chong-Gossard (2008) 11.

${ }^{26}$ Chong-Gossard (2008) 15.

${ }^{27}$ Kirkwood (1947) TV.

${ }^{28}$ Kastely (1993) 1039-40.

${ }^{29}$ Conacher (1961) 26.

${ }^{30}$ Conacher (1961) 20. 
لقد خططت هيكابى لاستدراج بوليميستور وطفليه إلى الخيمة حيث تجلس إنس النساء الأسيرات، بعد أن أوهمته بأنها تحتفظ في الخيمة بثروة من كنوز طروادة لأنس وأنها

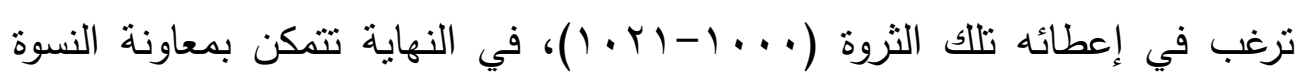

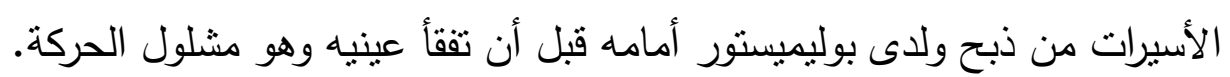

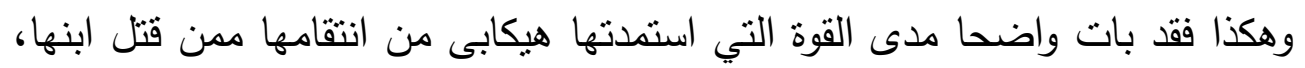

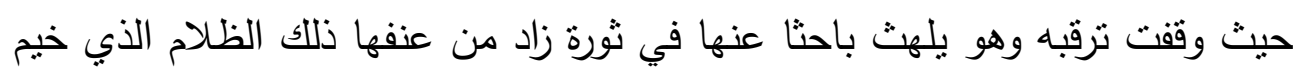

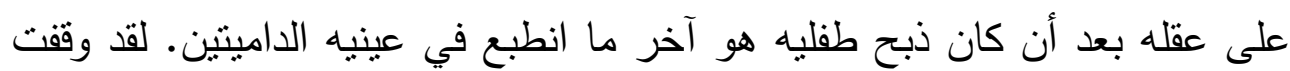
هيكابى المنتقمة تقول له:

\section{هيكابى: هيا اضرب بقوة، ولا تتوقف، ولتغلق الأبواب}

\section{ولكناك لن ترى ثانية الضوء بعينيك}

ولن ترى أولادك أحياء بعد أن قتلتهم أنا.

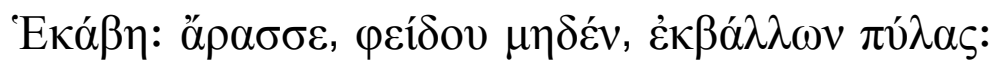

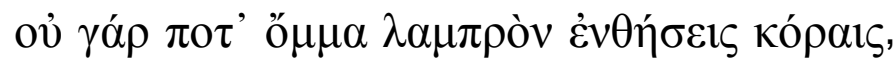

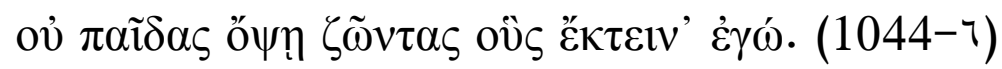

ومن الواضح في هذه الابيات أن هيكابى تتلذذ بانتقامها من بوليميستور

وكأنها جعلت من انتقامها سلاحا نفسيا استعملته في الانتقام لنفسها ولأبنائها

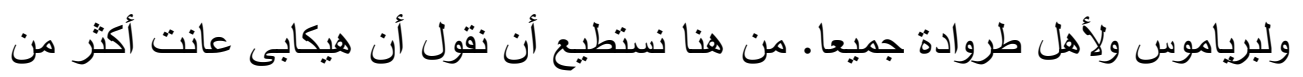

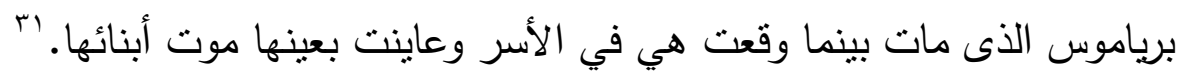

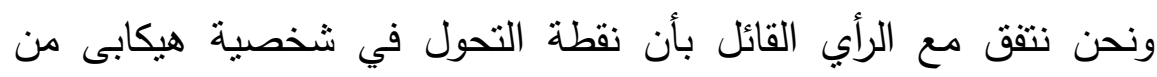

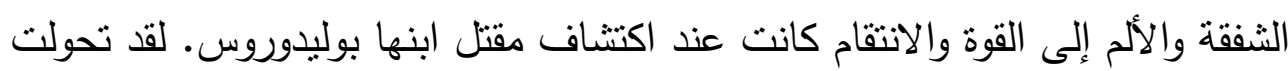

${ }^{31}$ Due, C. (2006). The Captive Woman's Lament in Greek Tragedy. University of Texas Press. P.118. 


\section{هيكابي يوريبيديس}

هيكابى إلى نفس الوحش الذى اتهمت به بوليميستور من قبل، وظهر ذللك واضحا في قتلها لأبنائه.

وبالرغم من أنه كان علينا أن نتوقع انتقام هيكابى لمصرع ابنها، لكن ربما لم

نكن لنتوقع تلك الوحشية في الانتقام. بّ أما هيكابى نفسها فلم يعد يهمها سوى أنها جعلت بوليميستور يدفع لها ثمن جريمته:

\section{هيكابى: لقد انتقمت}

$$
\text { منגd }
$$

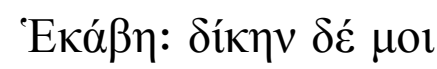

$\delta \varepsilon ́ \delta \omega \kappa \varepsilon \cdot(1052-3)$

لم يكن التغير المفاجئ فى السلوك من نصيب هيكابى فقط، بل أصاب بوليميستور أيضا، فقد تحول من ملك كان يدعى النبل في السلوك إلى وحش كاسر يبحث عن فريسته التي إن أمسك بها فسيمقها إربا ويطحن عظامها ويشرب من دمها بوريا حتى يرتوى ويشفى غليله:

بوليميستور: صمتا، فإنتي أسمع صوت خطوات

تلكل النسوة المتسللة. ترى هل أققز

عليهن حتى أمزق لحمهن وعظامهن.

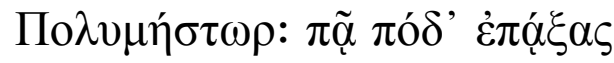

$\sigma \alpha \rho \kappa \tilde{\omega} v$ ỏ $\sigma \tau \varepsilon \dot{\varepsilon} \omega v \tau^{\prime} \dot{\varepsilon} \mu \pi \lambda \eta \sigma \theta \tilde{\omega}$,

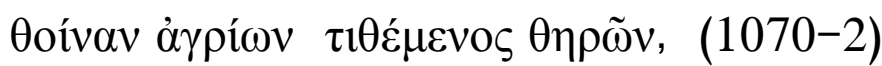

ويمكننا أن نلاحظ أنه بعد أن تمكنت هيكابى من تتفيذ انتقامها فإنها تعود إلى

هدوئها الذي تغلفه اللهجة الساخرة من بوليميستور الذي سقط في فخ الغضب وأصبح

${ }^{32}$ Chong-Gossard (2008) 95, Faas, E. (1984). Tragedy and After. Euripides, Shakespeare and Goethe. Queen's University Press. P. 21.

${ }^{33}$ Kirkwood (1947) 62. 
يبدو كثخص مجنون يفتقر إلى المنطق. لكن الدفاجآت لم تتنهي بعد، خاصة عندما

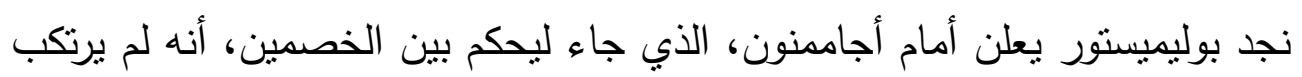

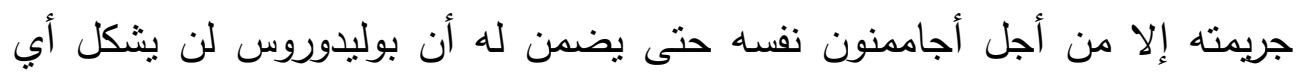
تهديد للإغريق في المستقبل.

من هنا يعلن بوليميستور أن ما ارتكبه لم يكن سوى تعبير عملي عن تحالفه مع أجامهنون وحرصه على سلامته:

بوليميستور : لقد قتلت ذلك الابن. ولتسمع السبب الذي وحري جعلني أقتله حتى تعرف أنى كنت حكيما فيما فعلت. لقد خثيت، إذا ما تركت عدوكم هذا على قيد فيد الحياة، أن يعيد إنثاء مدينة طروادة مرة أخرى ويعمرها بالسكان.

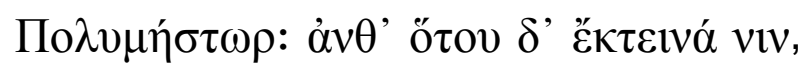

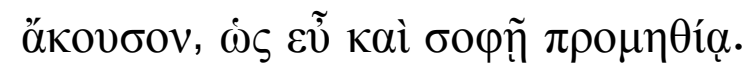

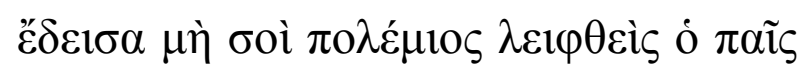

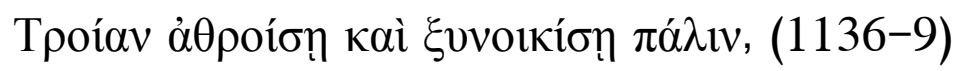
ومما لا شك فيه أن بوليميستور كان بالفعل حاد الذكاء ليس في جريمته التي

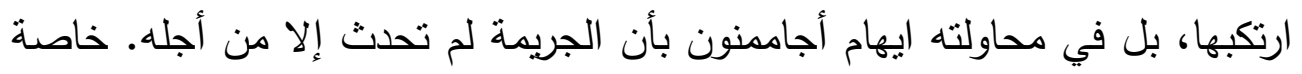

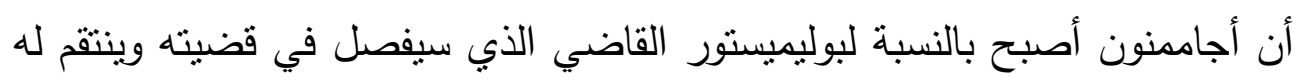

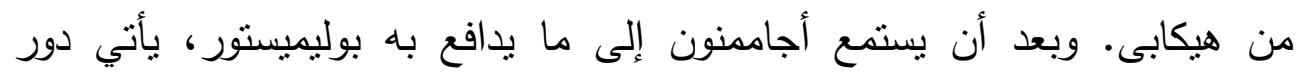

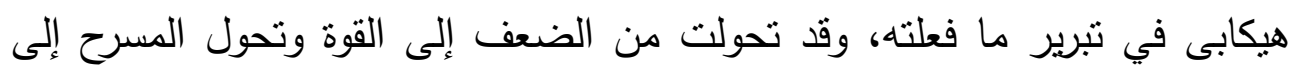

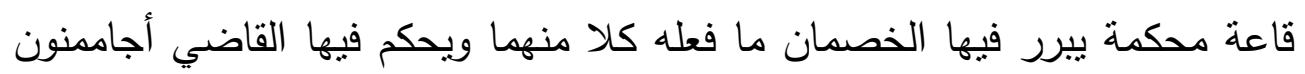
ويصير فيها الجمهور هيئة من المحلفين. 


\section{هيكابي يوريبيديس}

وبيدو لنا أن هيكابى، في سياق تبربرها لما فعلت، تتحدث كملكة وتأخذ لهجتها شكل الخطاب السياسي، خاصة عندما تعلن أن البرابرة، الذي ينتمي إليهم

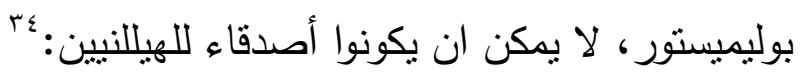

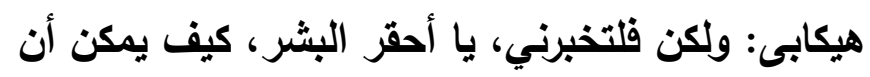

يصبح جنس بريري صديقا للإغريق؟

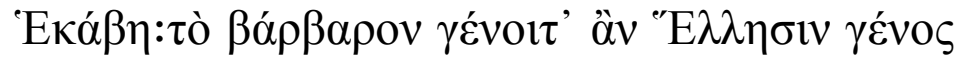

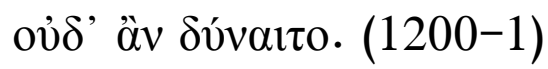

لكننا نلاحظ أن هيكابى في مرافعتها كانت قد نست أن ما قالته قد ينطبق

على الطرواديين أنفسهم، بوصفهم جنسا من البرابرة الذين لم يكونوا فقط أصدقاء للهيللنيين ولكنهم ولا يزالوا أعداء للإغريق. لكنها في هذا السياق تلعب دورا سياسيا في الرد على بوليميستور الذي أراد أن يحرك في نفس أجاممنون النزعة السياسية باعتباره

قائد الجيوش الإغريقية. ثم تستمر هيكابى في مرافعتها ضد بوليميستور، حيث تقول: هيكابى: لكن عندما أفل نجمنا ويعدنا عن الأضواء هرئ

وغطى الاخان الأي أشعله الأعداء سماء المدينة،

عندئذ قتلت الضيف الاي أتى إلى قصرك.

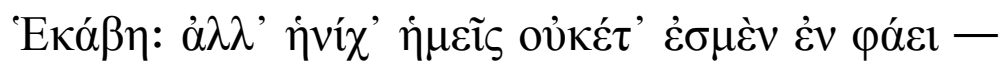

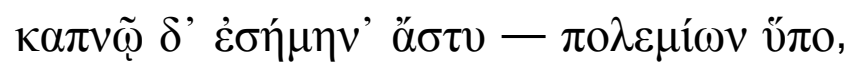

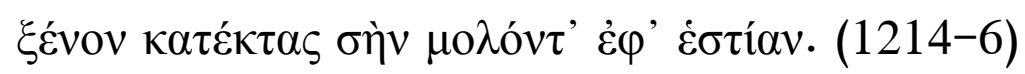

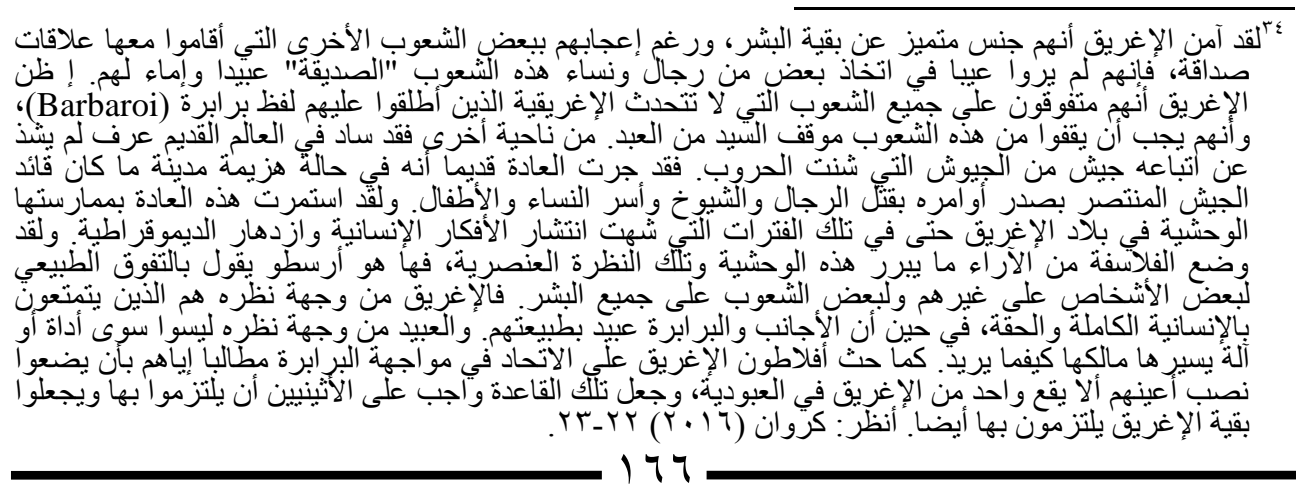


بعد أن استمع أجاممنون إلى كلا من بوليميستور وهيكابى، يأني حكمه

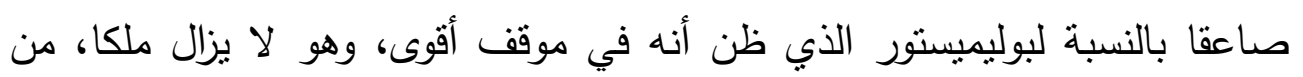

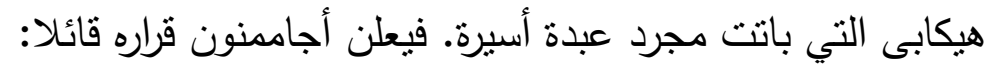
أجاممنون: ليس من أجل خاطري ولا من أجل الآخيين

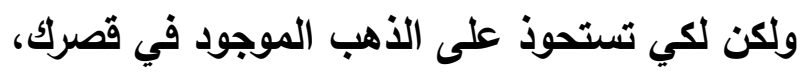

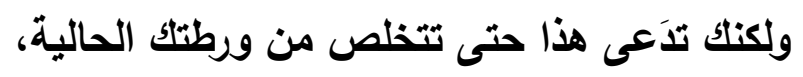

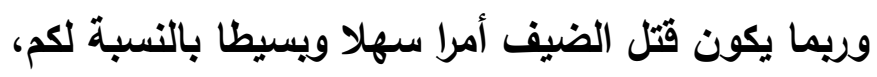
ولكنه بالنسبة لنا نحن الإغريق فهذا أمر مشين.

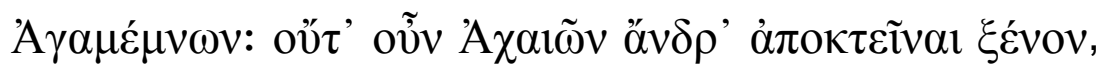

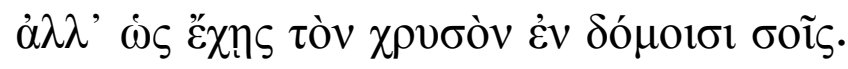

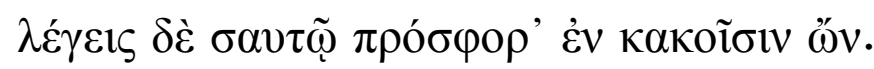

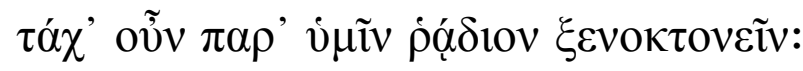

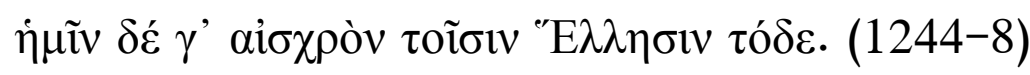
إن قرار أجاممنون بالحكم لصالح هيكابى لا يضع نهاية للتغيرات والتحولات

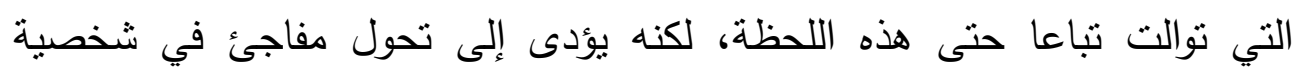

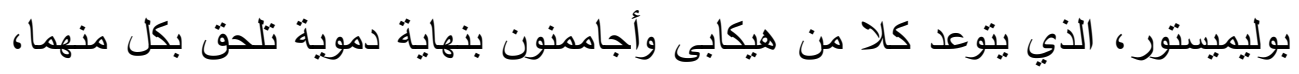

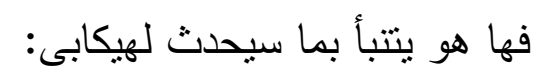

بوليميستور: قبر كلبة بائسة، وسوف يكون علامة للبحارة.

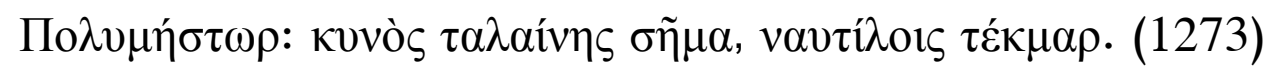
ويبدو أن بوليميستور كان يتوقع أن تسخر منه هيكابى، لذلك قرر أن يلقى لها بنبوعته

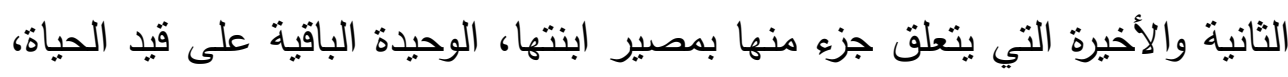
كاساندرا: 


\section{هيكابي يوريبيديس}

\section{بوليميستور : سوف تقتلها زوجة هذا الرجل، التي تحرس منزله بتفان.}

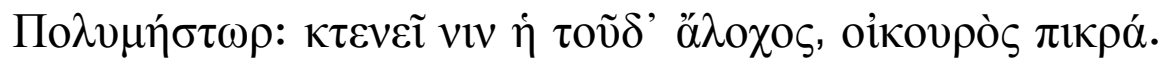

$$
\text { كما يتتبأ كذلك بمصبر أجاممنون: }
$$

بوليميستور: (لأجاممنون) وسوف تفعل بك نفس الشيء وهي ترفع بلطتها عاليا.

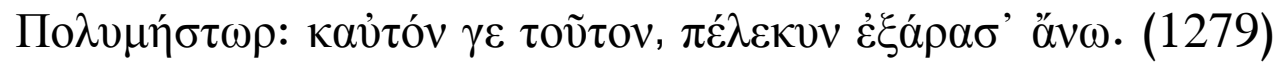

وهكذا يُلقى بوليميستور بنبوءته الأخيرة التي يؤكد فيها أن أجاممنون نفسه

سوف يلقى حتفه على يد زوجته كليتمنسترا بعد عودته إلى قصره في أرجوس. وكأن بوليميستور الغاضب يلقى بالنبوءة التي تخص ما هو آت ويحل بذلك محل أن Deus ex Machina

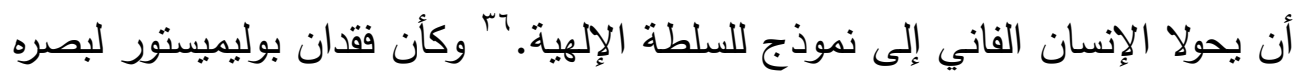

$$
\text { جعله يرى ما سيحدث في المستقبل. }
$$

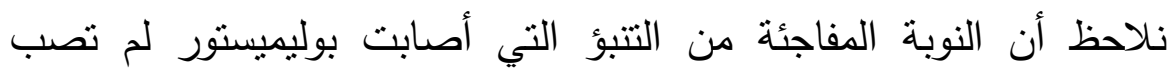

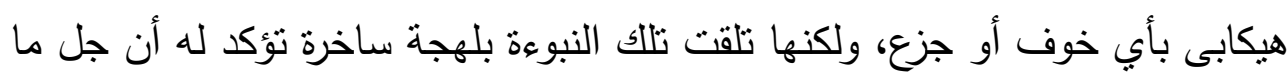

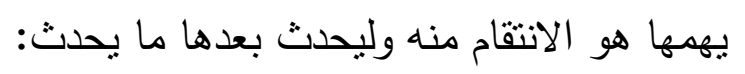

$$
\text { هيكابى: لا شيء يهمني سوى أنى انتقت منك. }
$$

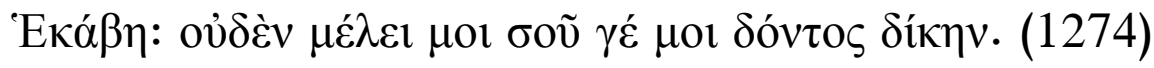
وهكذا توضح كلمات هيكابى أن الانتقام من بوليميستور كان أمراً حتميا

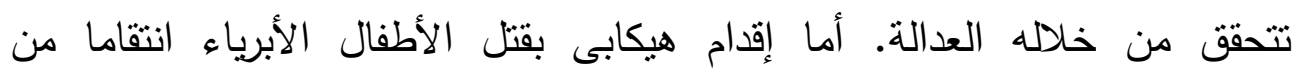

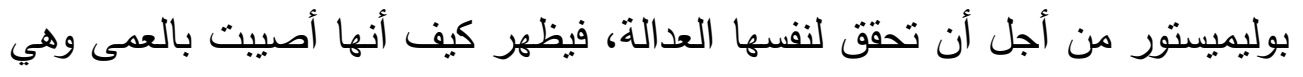

${ }^{35}$ Schuren (1980) 93.

${ }^{36}$ Dunn, F. M. (1996). Tragedy's End. Closure and Innovation in Euripidean Drama. Oxford University Press. 411, Yoon, F. (2012). The Use of Anonymous Characters in Greek Tragedy. The Shaping of Heroes. Leiden. Boston. P. 24. 
تحقق العدالة بإيذاء الأبرياء. كأن هذا العمى أصبح حتميا في ظل ظروف غير عادلة، وهي بذلك لا تختلف عن أوديسيوس وأجامهنون.

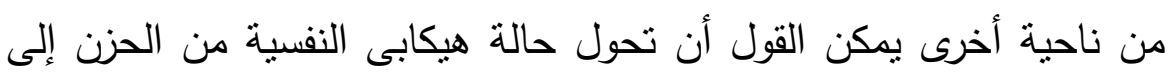

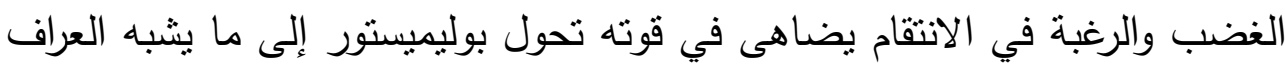

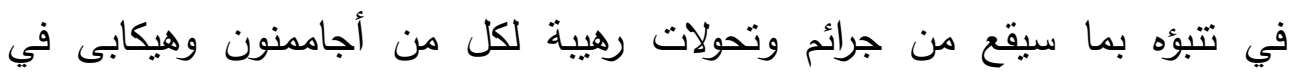

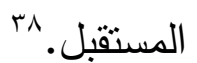

وقد يصاب المتفرج بالدهشة من تلك النبوءات التي تنزامن مع اقتراب نهاية

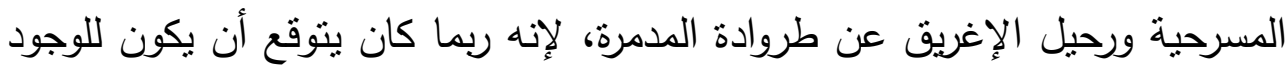

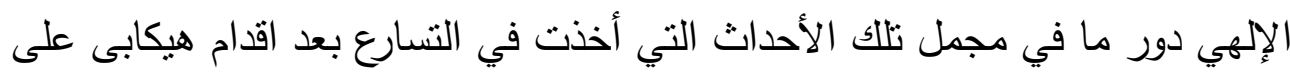

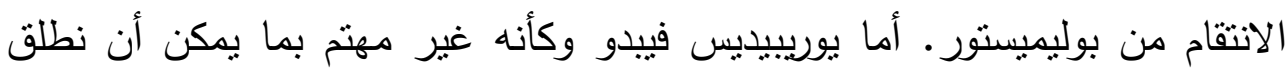
عليه الحتمية في الفعل أو التدخل الإلهي لإنهاء سلسلة منرابطة من الأحداث، لكنه

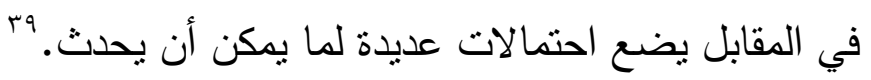

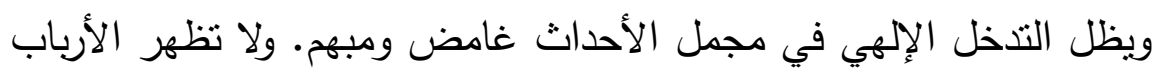
عند يوريبيديس في مسرحية هيكابى كحقيقة مطلقة ولكنها ظهرت كملامح للإيمان الثخصي والنزعات التي تحدد التغير في المشاعر والأخلاقيات لاى شخصئيلياته

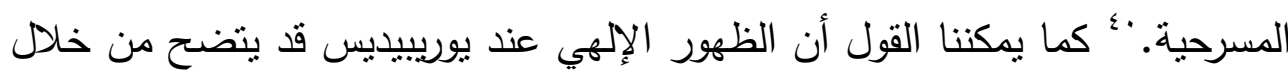

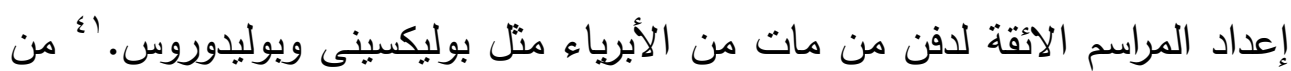

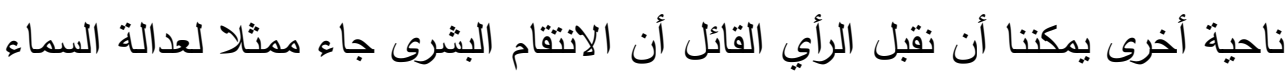

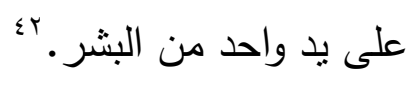

${ }^{37}$ Kastely (1993) 1046-7.

${ }^{38}$ Dunn (1996) 41.

${ }^{39}$ Love (2006) 13.

${ }^{40}$ Segal (1989) 10, 17.

${ }^{41}$ Segal (1989) 21.

${ }^{42}$ Hall, E. (2010). Suffering under the Sun. Oxford University press. P. 81. 


\section{هيكابي يوريبيديس}

وقد يصبح المغزى الدرامي للمسرحية الذي يصل إليه المتفرج مع معاينته ما

آلت إليه الأحداث هو كيفية تحايل الإنسان في استجابته وتعامله مع الشر • وأن يوريبيديس لم يهتم بانتهاكات القانون البشرى ولكنه يهنم برد فعل المجتمع تجاه تلك الانتهاكات. فعندما يتقبل البشر تللك الانتهاكات تموت العدالة الإنسانية، وتبقى القوة الفلسفية لمشكلة تطبيق العدالة كامنة في تعمد كل فرد إغفال مسئوليته الشخصية عن أفعاله وإلحاق الأذى بالآخرين. باء وهكا تتبخر كل معانى الولاء والثقة والثرف و تذهب هباء منثورا، وتحل بدلا منها أشياء أخرى تتمثل في التمسك بالثروة والقوة والانتقام.؛؛ فكل فرد يعمل وفق دوافع محددة تتفق مع وحشيته المفرطة التي هي المصدر الطبيعي لكل أفعاله. ه؛ إذاً فمن يمكن أن يمثل العظمة الإنسانية في المسرحية؟ إنهم ليسوا الملوك الذين يملكون السلطة. لكن العظمة الإنسانية قد تتمثل في بوليدوروس الذي مات أو في هؤلاء الجنود المجهولين، الذين ييقوا جميعا على هامش الأحداث. ب؛ كل ذلك يحدث عندما

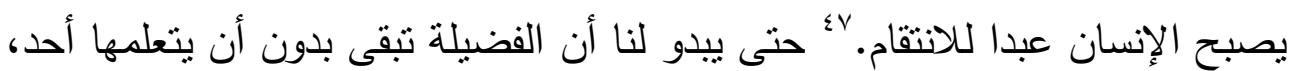
كما يصيب الفساد النفوس الصالحة وبنهار السمو جاثيا. ^؛

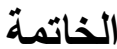

لم تسقط طروادة عندما تمكن الإغريق من اقتحامها وتذميرها، ولكنها سقطت قبل ذلك بأمد بعيد. سقطت طروادة عندما اعتبرت الأسرة المالكة أن وجود هيللينى بينهم ليس جريمة ولا دليلا على الخيانة، سقطت لأنها باتت تحمى الخيانة وتدافع عنها وأصبح دمارها أمرا حتميا.

\footnotetext{
${ }^{43}$ Kastely (1993) $104 \cdot-1$.

${ }^{44}$ Reckford (1991) 35.

${ }^{45}$ Abrahamson (1952) 123.

${ }^{46}$ Abrahamson (1952) 129.

${ }^{47}$ Kastely (1993) 1044.

${ }^{48}$ Reckford (1991) 33.
} 
وبعد اقتحام الإغريق أسوار طروادة يتحقق العدل، فكان من العدل أن يموت برياموس وتلحق به بوليكسينى، ذبيحة على قبر أخيلليوس. وكان من العدل أن تقع كاساندرا وهيكابى في الأسر. ومع سقوط طروادة تسقط كل الأفنعة عن الملوك بك الفاسدين. فبوليميستور يقرر قتل بوليدوروس، وتلهث هيكابى وهي تسعى للانتقام من بوليميستور، فتقتل ولديه أمام عينيه ثم تمعن في انتقامها بأن تققأ عينيه. إنه عالم الملوك الذي لم يعي ثقل ما يحمله على عاتقيه من مسئوليات وكيف انه هو الذي لهي يمثل عقل الدولة والحكمة التي لابد أن يتحلى بها حتى في أحلك الظروف. لكن تغيب الحكمة وتتأجج الرغبة وتنيطر الثهوة على النفوس البشرية. من هنا يصبح التحول في السلوك الإنساني هو ما يؤدى إلى اتخاذ القرار المفاجئ وهو ما يجعلنا نقف أمام ما يحدث في حالة من الصدمة إزاء ثلاك التحولات وما يعقبها من نتائج. وختاما، نجيب على النقاط الأربعة التي أشرنا إليها في مقدمة البحث وهي كالتالي: 1- يلقى يوريبيديس الضوء في مسرحية هيكابى على أحداث ما بعد سقوط طروادة

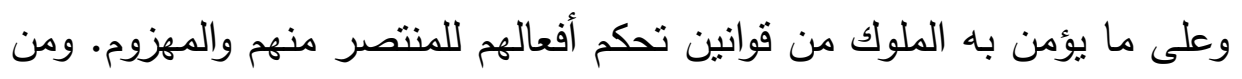
خلال مسرحية هيكابى عبر يوريبيديس على ما وصل إليه حال أثنيا بعد الحرب فوله

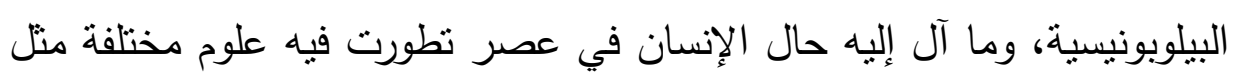
الطب والفلك والأنثروبولوجيا والفيزياء. كل ذلك ساهم في تقويض إيمان البشر بالقانون البشرى والقانون السماوي. ૧؛ إلى جانب ذلك نلوح الإرادة الإلهية في الأفق وكأنها نوع من الانتقام الدموي الذي لا يختلف عن الإرادة البشرية التي تسعى وراء نفس الفعل. فبينما كان المشاهد يظن أن العويل والنحيب هما مشهد النهاية الذي تصاحبه سحب الدخان من مدينة طروادة المهزومة، إلا أنه وجد نفسه أمام بداية جديدة تمنلت في المواجهة بين المنتصر والمهزوم - كما كانت المواجهة

${ }^{49}$ Reckford (1991) 38. 


\section{هيكابي يوريبيديس}

بين كلا من أوديسيوس وأجاممنون وبين هيكابى-ثم بين رموز الخيانة قبل وبعد سقوط طروادة - كما تمنل ذلك في المواجهة بين هيكابى وبوليميستور . فتارة تظهر تلك الإرادة في التضحية ببوليكسينى، ثم تعود للظهور في رغبة هيكابى في الانتقام من بوليميستور من ناحية وتتحى أجاممنون عن طريق تلك الرغبة من ناحية أخرى. إلى أن تظهر جليا في الأفق من خلال نبؤه بوليميستور الملوثة بنفس الرغبة الثرسة في الانتقام. ويصبح الانتقام في مسرحية هيكابى هو التحول غير متوقع، والذي يؤدى بدوره إلى إحداث المفاجئة لما ينتج عنه من احداث. ويمكننا القول إن دراما هيكابى تتحول إلى المزيد من الألم حيث يقف المشاهد شاهدا على كل ذلك الألم. يصبح كل ذلك بلا معنى لو لم يؤدى إلى أي نهاية. •ْ لكننا قد نختلف مع الرأي القائل أن مسرحية هيكابى لا تتعامل مع الثفقة من المنظور الإنساني العادي. لكنها تتعامل مع صورة العدو المهزوم.' وذلك لأن مسرحية هيكابى أظهرت أيضا مفهوم الثفقة لدى المنتصر في الحرب، فقد أبرز يوريبيديس هذا المفهوم من هن هن خلال أفعال كلا من أوديسيوس وأجاممنون تجاه الجانب المهزوم في الحرب والذي تمنل في بوليكسينى وهيكابى. وهناك نوع من التشابه بين مقتل بوليكسينى وبوليدوروس وبين مقتل ولدى بوليميستور، حيث يمثل كل هؤلاء القتلى، وهم الأبناء، الحلقة الأخيرة التي قد تصل الماضي بالمستقبل. هكذا تأتى الهزيمة الحضارية التي يصاحبها فساد النفس البشرية، فتسقط معها القيم الإنسانية. من ثم تصبح العودة إلى القيم الإنسانية دربا من المستحيل،

${ }^{51}$ Tzanetou, A. (2012). City of the Suppliants. Tragedy and the Athenian Empire. University of Texas Press. P.131. 
ويتمسك الانسان برغباته ومبرراته فيما أقدم عليه من قبل من أفعال وفى ما هو

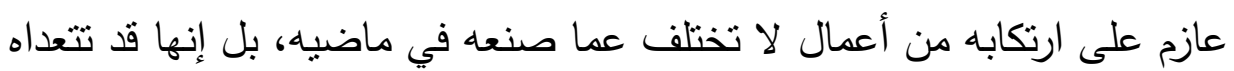
لتصل به إلى أن يفق هويته ويكتسب ملامح غريبة ترسم لله مستقبله وتتوهو ماضبه.

r- قام يوريبيديس برسم ملامح هيكابى، في بداية المسرحية، على أنها الأسيرة

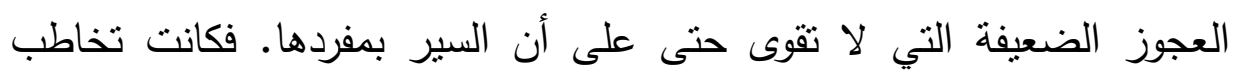

$$
\text { الأسيرات من نساء طروادة وتقول: }
$$

هيكابى: أيتها الطرواديات، فلتقدن رفيقتكن في العبودية،

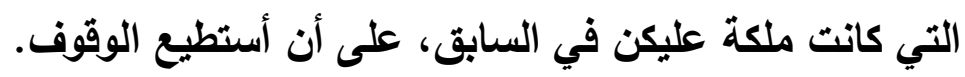

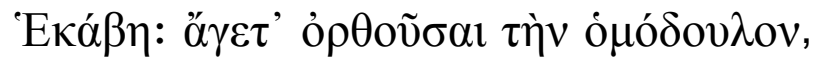

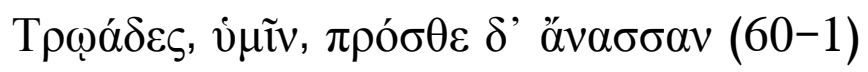

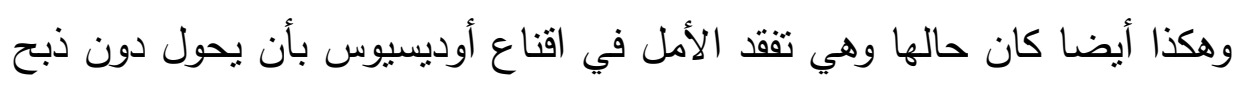

$$
\text { بوليكسينى على قبر أخيلليوس: }
$$

هيكابى: ولكن، أيها الصديق المبجل فلتهتم بأمري

$$
\text { ولترحمني. }
$$

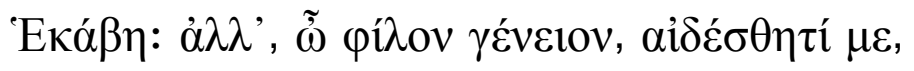

$$
\text { oúktıpov (286-7) }
$$

كانت شخصية هيكابى تتميز بجاذبية خاصة عبر الأجيال لكل من بريد أن يدلل

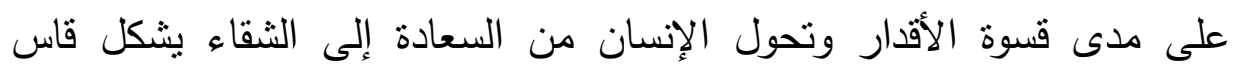

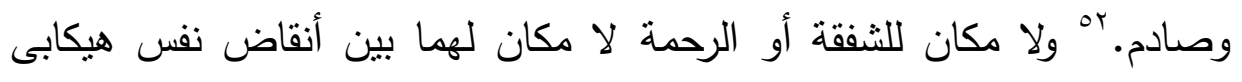

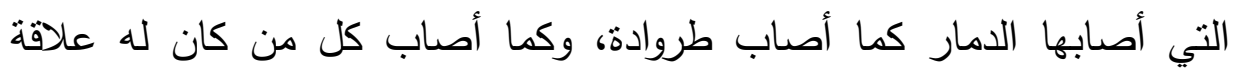
بحرب طروادة نفسها سواء كان منتصرا أو مهزوما. 


\section{هيكابي يوريبيديس}

هذا ما قام به يوريبيديس عندما قام برسم الملامح الجديدة لشخصية هيكابى، والتي قد تبدو للوهلة الأولى وكأنها نوع من الصدمة الأخلاقية بالنسبة للمشاهد الذي لم يكن يتوقع هذا التحول المفاجئ في شخصية هيكابى الضعيفة. خاصة عندما أعلنت أنه لم يعد يهمها ما قد يحدث لها طاما أنها انتقمت لنفسها: هيكابى: لا شيء يهمني سوى أنى انتقمت منك.

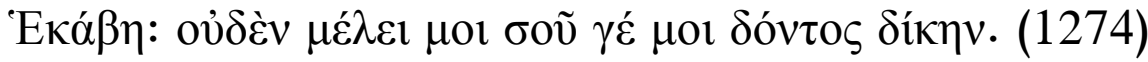
r -لقد بدت نبوءة بوليميستور وكأنها رغبة أخرى في الانتقام، تغلفها غطرسة الملك الذي امتلك السلطة والمال، بل وظن أن نفوذه قد يشمل حلفاءه من الإغريق وعلى رأسهم أجاممنون. وهذا ما قد يصيب المشاهد بالحيرة. فلقد ألقى الملك الذي يلهث ويصرخ وعيناه تدميان بالنبوءة، ساعيا وراء الانتقام ممن يظن أنها خدعته. فتختفى النبوءة حتى يتخلى عنه حليفه ولا يحكم له بالحق في القصاص من عدوته هيكابى. حينها فقط تتطلق النبوءة التي ربما كان بوليميستور يعلمها من قبل، لكنه لم بنطق بها إلا كتعبير أخير عن الغطرسة التي تدفع صاحبها لتهديد خصمه حتى وإن كان لا بستطيع تتفيذ ما بطمح إليه. ع-لقد استطاع يوريبيديس أن يجعل من التحول في الفعل أداة تمكنه من اخراج المشاهد من طور الثفقة الذي سيطر عليه منذ بداية المسرحية إلى طور الذهول من قوة المفاجئة الناتجة عن التحول الجذري في سلوك نفس الثخصية التي كانت هي نقسها الباعث على احساسه بالثفقة من قبل. وقد يكون هذا التحول في الفعل هو السبب الرئيس في انعدام وجود الدور الإلهي المؤثز والمباشر في أحداث المسرحية منذ بدايتها إلى نهايتها. وهذا ما يمكن أن نعتبره أقوى مفاجآت المسرحية التي لم يتوقعها المشناهد نفسه. 


$$
\text { قائمة المراجع }
$$

$$
\text { أولا: المصادر : }
$$

Euripides. Euripidis Fabulae, vol. 1. Gilbert Murray. Oxford. Clarendon Press, Oxford. 1902.

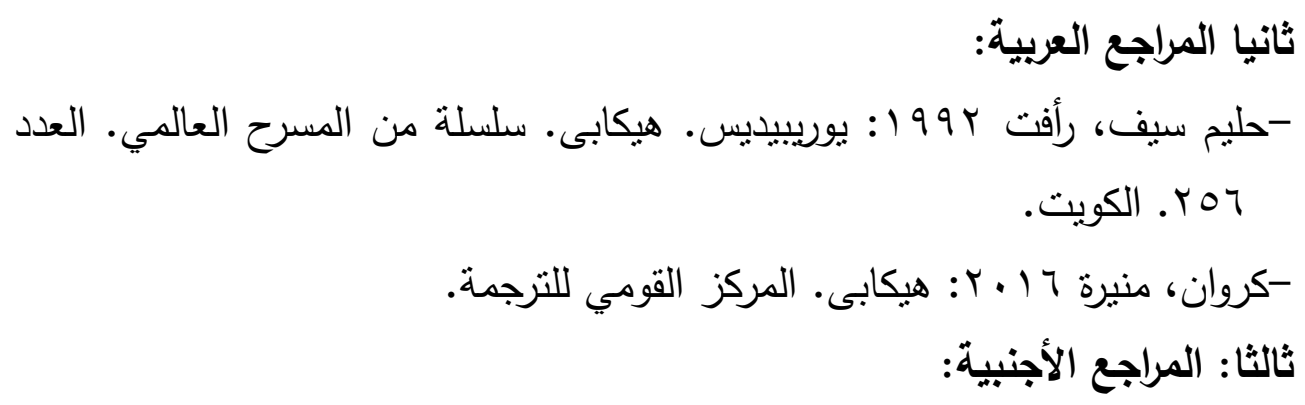

Abrahamson, E. L.1952.” Euripides’ Tragedy of Hecuba”, TAPhA, Vol. 83, 120-129.

Chong-Gossard, J. H. 2008., "Gender and Communication in Euripides' Plays. Between Song and Silence", In Boter, G. J \& Others. Monographs on Greek and Roman Language and Literature. Mnemosyne Supplements, Vol 296, 1-263.

Conacher, D. J. 1961., "Euripides' Hecuba", AJPh, Vol. 82, No. 1, 1-26.

Dunn, F. M. 1996. Tragedy's End. Closure and Innovation in Euripidean Drama. Oxford University Press.

Due, C. 2006. The Captive Woman's Lament in Greek Tragedy. University of Texas Press.

Faas, E. 1984. Tragedy and After. Euripides, Shakespeare and Goethe. Queen's University Press.

Foley, H. P. 2001. Female Acts in Greek Tragedy. Princeton University Press.

Hall, E. 2010. Suffering under the Sun. Oxford University press.

Kastely, J. L. 1993., "Violence and Rhetoric in Euripides' Hecuba", PMLA, Vol. 108, No. 5, 1036-49.

Kirkwood, G. M. 1947.," Hecuba and Nomos”, TAPhA, Vol. 78, 61-68.

Love, H. 2009. Introductions and Translations to the Plays of Sophocles and Euripides. Vol. 1. Cambridge Scholars Press.

Pedrick, V. 2007. Euripides, Freud, and the Romance of Belonging. John Hopkins University Press. 


\section{هيكابي يوريبيديس}

Rehm, R. 2002. The Play of Space. Spatial Transformation in Greek Tragedy. Princeton University Press.

Reckford, K., (1991), "Pity and Terror in Euripides' "Hecuba"', Arion, Third Series, Vol. 1, No. 2, 24-43.

Sansone, D. 2012. Greek Tragedy and the Invention of Rhetoric. WileyBlackwell.

Schuren, L. 1980. Shared Storytelling in Euripidean Stichomythia. LeidenBoston.

Segal, C. 1989., "The Problem of the Gods in Euripides' Hecuba”, Materiali e discussioni per l'analisi dei testi classici, 22, 9-21.

Sullivan, S. D. 2000. Euripides' Use of Psychological Terminology. Queen's University Press.

Tzanetou, A. 2012. City of the Suppliants. Tragedy and the Athenian Empire. University of Texas Press.

Worman, N. 2002. The Cast of Character. Style in Greek Literature. University of Texas Press.

Yoon, F. 2012. The Use of Anonymous Characters in Greek Tragedy. The Shaping of Heroes. Leiden. Boston. 